\title{
A Simple and Efficient Approach to the $N$-Amination of
}

\section{Oxazolidinones Using Monochloroamine}

Uyen Huynh, ${ }^{\dagger}$ Md. Nasir Uddin, ${ }^{\dagger}$ Sarah E. Wengryniuk, ${ }^{\dagger}$ Stacey L. McDonald,$\S$ and Don M. Coltart ${ }^{*}{ }^{\dagger}$

${ }^{\dagger}$ Department of Chemistry, University of Houston, Houston, TX 77204-5003

* Current address: Department of Chemistry, Temple University, Philadelphia, PA 19122

$\S$ Current address: Eshelman School of Pharmacy, University of North Carolina at Chapel Hill, Chapel Hill, NC 27599

*dcoltart@uh.edu

\section{RECEIVED DATE}

\begin{abstract}
Chiral nonracemic $\mathrm{N}$-amino cyclic carbamates (ACCs) are important auxiliaries for certain asymmetric transformations. In the past they have been synthesized from oxazolidinones using methods that require the preparation and use of non-atom economical aminating agents that can be difficult to prepare, and often strong bases. In what follows we describe a mild and operationally simple method for the direct $\mathrm{N}$-amination of oxazolidinones that uses $\mathrm{NH}_{2} \mathrm{Cl}$ derived from commercial bleach.
\end{abstract}

Chiral nonracemic $N$-amino cyclic carbamates (ACCs) have gained attention as auxiliaries for important asymmetric transformations. The synthetic utility of these systems was first demonstrated by Friestad in 2000 (Scheme 1a). ${ }^{1}$ In that work, hydrazones (5) obtained from the condensation of ACCs and aldehydes were found to undergo diasteroselective radical additions to produce hydrazines (6). Subsequent acylation and then cleavage of the nitrogen-nitrogen bond furnished the corresponding 
amines (7) with excellent overall levels of asymmetric induction. Prior to these studies, no such methods were available for the direct asymmetric alkylation of imines via radical methods. Further refinement of this method by Friestad ${ }^{2}$ resulted in a manganese-mediated radical addition procedure that is tolerant of an impressive range of functional groups and alkyl motifs. ${ }^{3}$ The latter procedure also forms the basis of an efficient hybrid radical-ionic annulation method that enables the highly stereoselective synthesis of pyrrolidines and piperidines ( $c f$. Scheme 1b). ${ }^{3}$ Aldehyde-derived ACC hydrazones have also been shown to undergo In-promoted allylation using either an allyl silane ${ }^{4}$ species or allyl iodide ${ }^{5}$ as the allyl source. Asymmetric Mannich-type reactions between aldehyde-derived ACC hydrazones and a variety of silyl enol ethers also proceeds with excellent levels of asymmetric induction to give $\beta$-amino carboxylate derivatives. ${ }^{6}$ Somewhat more recently we introduced the use of ACC hydrazones as a simple and effective tool for the asymmetric $\alpha$-alkylation and $\alpha, \alpha$-bisalkylation of ketones $\left(c f\right.$. Scheme 1c). ${ }^{7}$ In contrast to other asymmetric alkylation methods, ${ }^{8}$ these auxiliaries are both easily introduced into and removed from ketones, with near quantitative recovery. Moreover, deprotonation is rapid and alkylation does not require extreme low temperature, yet it proceeds with excellent stereoselectivity and in excellent yield.

An obvious and straightforward approach to these synthetically useful ACCs is via the direct $N$ amination of oxazolidinones. Oxazolidinones are readily accessible from $\alpha$-amino acids using wellestablished procedures, and a large number are also commercially available. Consequently, the ability to directly $\mathrm{N}$-aminate these species would provide rapid access to a range of ACCs. Indeed, such an approach has been used in the past. ${ }^{9}$ Unfortunately the reported methods for the $N$-amination of oxazolidines require the sometimes cumbersome preparation and use of non-atom economical aminating agents (Figure 1), and often strong bases. In what follows, we describe an operationally simple, mild, and inexpensive procedure for the $N$-amination of oxazolidinones using atom economical monochloroamine as the aminating agent, itself easily derived from commercially available bleach. The resulting ACCs are obtained in excellent yield. 


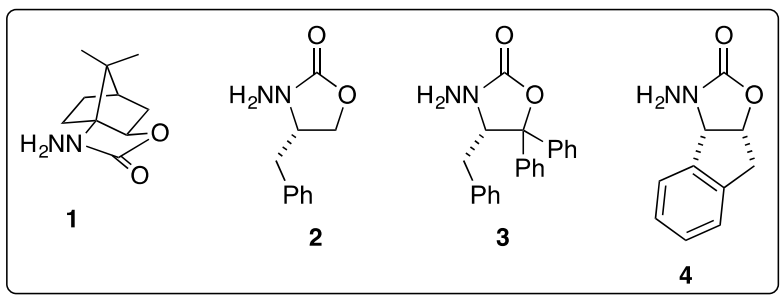

a) Enantioselective secondary amine synthesis

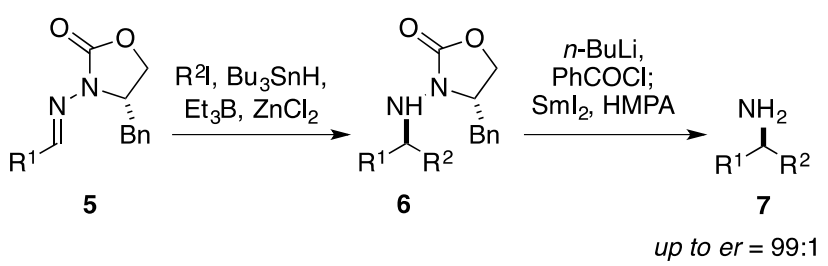

b) Enantioselective piperidine synthesis

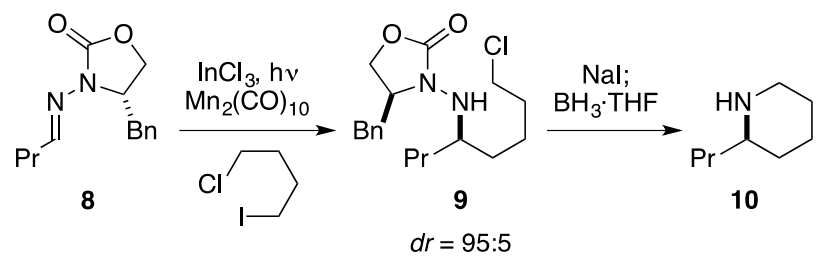

c) Enantioselective ACC ketone $\alpha$-alkylation

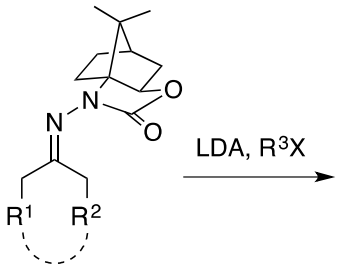

11

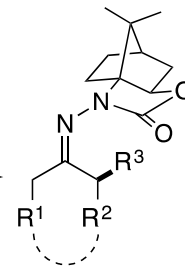

12

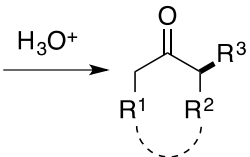

13

up to er $=99: 1$

Scheme 1. Representative asymmetric methods employing $N$-Amino cyclic carbamate hydrazones.

When we began our studies on the $N$-amination of oxazolidinones our main objective was to circumvent the use of the non-atom economical reagents listed in Figure 1. To do this, we first tried an indirect approach wherein we would conduct an $N$-nitrosylation, followed by a reduction of the nitrosyl

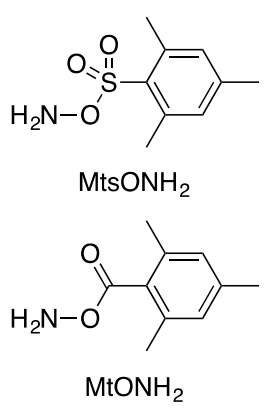<smiles>NOc1ccc([N+](=O)[O-])cc1[N+](=O)[O-]</smiles><smiles></smiles><smiles>CC(C)(C)C1(C(C)(C)C)NO1</smiles>

Figure 1. Aminating agents. 
group to generate the $N$-amino cyclic carbamate (Scheme 2a). To test this idea, we first attempted the nitrosylation of 17 using nitrous acid, ${ }^{10,11}$ which produced the desired product (18) in $70 \%$, following silica gel chromatography (Scheme 2b). Nitrosylation was also tried using nitrosonium tetrafluoroborate, ${ }^{12}$ and produced an even better result, giving a $98 \%$ yield of product that, even in its crude form, was extremely pure ( $>98 \%$, as judged by ${ }^{1} \mathrm{H}$ NMR).

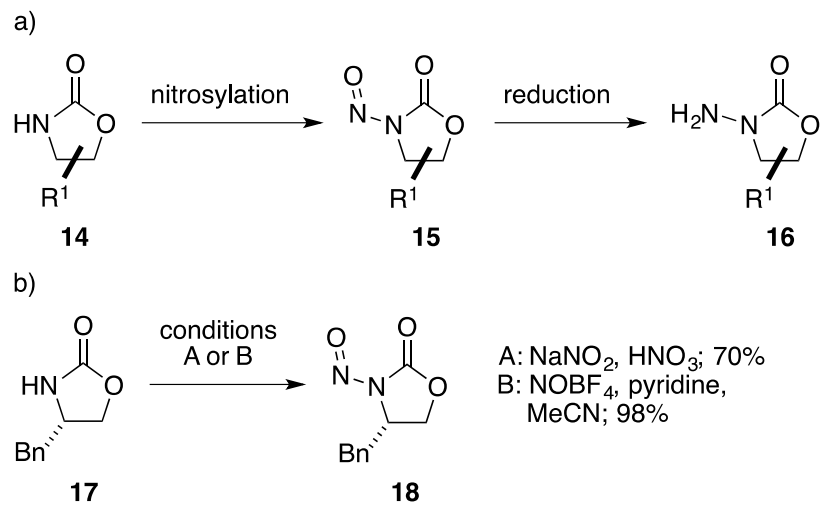

Scheme 2. Indirect amination approach.

With compound 18 in hand, we tried the reduction of the nitroso group. A common approach to performing this reduction is to use zinc in glacial acetic acid. ${ }^{12,13}$ However, in our system we found that this method gave at best a 60:40 mixture of hydrazide to oxazolidinone (Table 1). Modifications to the reaction conditions, including dilution of the acetic acid, and variation of the reaction time and temperature gave no improvement. We next tried the reduction using a Ti(II) complex, generated in situ by the reaction of $\mathrm{TiCl}_{4}$ and $\mathrm{Mg},{ }^{14}$ which gave an 85:15 ratio of desired hydrazide to oxazolidinone (Table 1). Unfortunately, despite this promising result, the use of these conditions for the reduction proved extremely inconsistent, and often resulted in complete over-reduction of the $N$-nitroso compound to the oxazolidinone.

Table 1. Nitroso group reduction. 


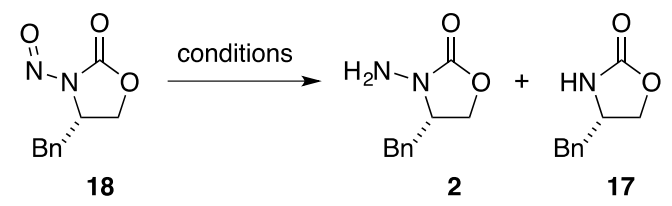

\begin{tabular}{lllll}
\hline entry & conditions & temp $\left({ }^{\circ} \mathrm{C}\right)$ & time $(\min )$ & $\mathbf{2 : 1 7}$ \\
\hline 1 & $\mathrm{Zn}, \mathrm{HOAc}$ & 10 & 40 & $50: 50$ \\
2 & $\mathrm{Zn}, \mathrm{HOAc}$ & 10 & 15 & $60: 40$ \\
3 & $\mathrm{Zn}, \mathrm{HOAc}, \mathrm{Et}_{2} \mathrm{O}$ & 0 & 15 & $60: 40$ \\
4 & $\mathrm{Zn}, \mathrm{HOAc}, \mathrm{Et}_{2} \mathrm{O}$ & 0 & 15 & $60: 40$ \\
5 & $\mathrm{TiCl}_{4}, \quad \mathrm{Mg}, \quad \mathrm{CH}_{2} \mathrm{Cl}_{2}, \mathrm{rt}$ & 10 & $85: 15^{a}$
\end{tabular}

${ }^{a}$ Best result of multiple attempts ranging from 0:100 to 85:15.

While we were conducting this work, we came across a report ${ }^{15}$ that showed that monochloramine $\left(\mathrm{NH}_{2} \mathrm{Cl}\right)$ could be used for the $\mathrm{N}$-amination of pyrroles and indoles. The $\mathrm{NH}_{2} \mathrm{Cl}$ was conveniently generated by combining $\mathrm{NH}_{4} \mathrm{Cl}, \mathrm{NH}_{4} \mathrm{OH}$, and $\mathrm{NaOCl}$ (in the form of commercial bleach) in $\mathrm{Et}_{2} \mathrm{O} .{ }^{16}$ Inspired by this work, we wondered about the possibility of using these conditions to effect the $N$-amination of oxazolidiones. To test this idea, oxazolidinone 17 was subjected to $t$-BuOK and then $\mathrm{NH}_{2} \mathrm{Cl}^{17}{ }^{17}$ We were pleased to find that the desired product (2) was indeed formed, but, unfortunately, in only $37 \%$ yield. Repeated attempts at the reaction gave variable results, with 2 being obtained in low to very good yield. The literature procedure that we were following called for the use of a nitrogen sparge during addition of $\mathrm{NH}_{2} \mathrm{Cl}$. In our hands, we found this sparging process to be problematic, as it caused solvent evaporation to occur in a manner that was difficult to regulate, which was likely the source of our inconsistent amination results. Fortunately, we found that in our system omitting the nitrogen sparge and just conducting the reaction under an Ar atmosphere led to consistently high conversions. After trying several variations of the reaction conditions, we found that use $t$-BuOK in THF, followed by addition of $\mathrm{NH}_{2} \mathrm{Cl}$ produced the desired $\mathrm{N}$-aminated hydrazide (2) with $97 \%$ conversion.

Table 2. Direct amination of oxazoidiones using chloramine ${ }^{a}$. 


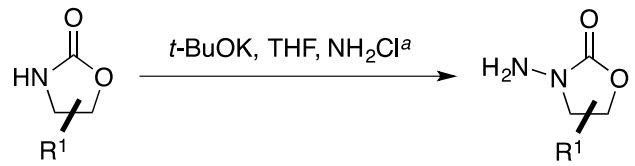

\begin{tabular}{|c|c|c|c|}
\hline entry & oxazolidinone & ACC & cont \\
\hline 1 & 19 & 1 & 93 \\
\hline 2 & $\begin{array}{ll}\mathrm{Bn} " \\
17\end{array}$ & 2 & 97 \\
\hline 3 & & 3 & 99 \\
\hline
\end{tabular}

20

4

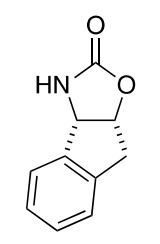

4

91

21

5

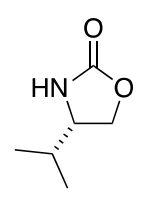

22

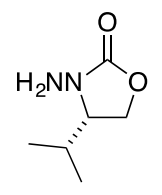

92

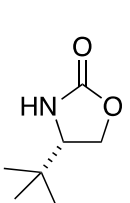

25

6

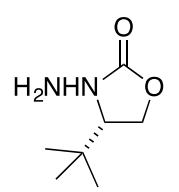

94

23

26

7
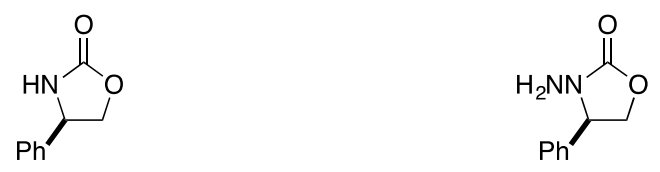

92

24

27 
${ }^{a}$ Prepared by combining $\mathrm{NH}_{4} \mathrm{OH}, \mathrm{NH}_{4} \mathrm{Cl}$, bleach, and $\mathrm{Et}_{2} \mathrm{O}$ (see the supporting information for details). ${ }^{b}$ Based on the ratio of ACC to unreacted oxazolidione in the crude reaction mixtre. Crude reaction mixtures contained only the ACC and oxazolidione.

Using these conditions, we carried out the $N$-amination of several different oxazolidinones, as shown in Table 2. In each case the desired product was obtained as a clean mixture along with only unreacted oxazolidinone. The extent of conversion to the $N$-aminated products was uniformly excellent (91-99\%). However, all attempts to increase the extent of conversion through modification of the reaction conditions were unsuccessful.

Table 3. Oxazolidinone amination and hydrazone formation.

\begin{tabular}{|c|c|c|c|c|c|}
\hline entry & oxazolidinone & conditions & $\mathrm{R} 2$ & $\begin{array}{c}\text { ACC } \\
\text { hydrazone }\end{array}$ & yield $(\%)$ \\
\hline 1 & 19 & A & $\mathrm{Me}$ & 28 & 72 \\
\hline 2 & 17 & A & $\mathrm{Me}$ & 29 & 85 \\
\hline 3 & 20 & A & $\mathrm{Me}$ & 30 & 90 \\
\hline 4 & 21 & A & $\mathrm{Me}$ & 31 & 91 \\
\hline 5 & 22 & A & $\mathrm{Me}$ & 32 & 85 \\
\hline 6 & 23 & A & $\mathrm{Me}$ & 33 & 90 \\
\hline 7 & 24 & A & $\mathrm{Me}$ & 34 & 91 \\
\hline 8 & 19 & B & $\mathrm{Et}$ & 35 & 92 \\
\hline 9 & 17 & $\mathrm{~B}$ & $\mathrm{Et}$ & 36 & 88 \\
\hline 10 & 20 & $\mathrm{~B}$ & $\mathrm{Et}$ & 37 & 93 \\
\hline 11 & 21 & $\mathrm{~B}$ & $\mathrm{Et}$ & 38 & 80 \\
\hline 12 & 22 & $\mathrm{~B}$ & $\mathrm{Et}$ & 39 & 83 \\
\hline 13 & 23 & $\mathrm{~B}$ & $\mathrm{Et}$ & 40 & 84 \\
\hline 14 & 24 & B & $\mathrm{Et}$ & 41 & 86 \\
\hline
\end{tabular}


Unfortunately, purification of the ACC from the unreacted oxazolidinone by chromatography proved extremely difficult. Thus, in an effort to purify the ACCs, an ethereal solution of the crude reaction mixture corresponding to entry 1 in Table 2 was treated with $\mathrm{HCl}$ gas to generate the $\mathrm{HCl}$ salt of 1. This proved extremely effective, as the salt was obtained in $82 \%$ yield over the two steps (amination; $\mathrm{HCl}$ sat formation) starting from 19. We next tried this approach using the crude reaction material corresponding to entry 2 of Table 2 . Unfortunately, the $\mathrm{HCl}$ salt obtained in this case was very hygroscopic and it could not be isolated in a manageable form.

Table 4. Conversion of acetone hydrazones to ACCs.

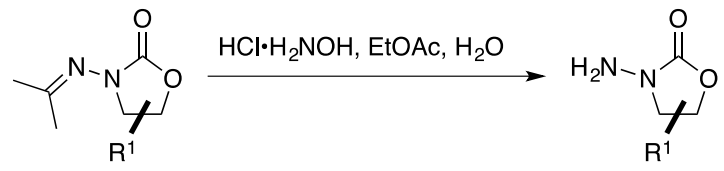

\begin{tabular}{llll}
\hline entry & ACC hydrazone & ACC & yield (\%) \\
\hline 1 & $\mathbf{2 8}$ & $\mathbf{1}$ & 95 \\
2 & $\mathbf{2 9}$ & $\mathbf{2}$ & 89 \\
3 & $\mathbf{3 0}$ & $\mathbf{3}$ & 92 \\
4 & $\mathbf{3 1}$ & $\mathbf{4}$ & 81 \\
5 & $\mathbf{3 2}$ & $\mathbf{2 5}$ & 93 \\
6 & $\mathbf{3 3}$ & $\mathbf{2 6}$ & 91 \\
7 & $\mathbf{3 4}$ & $\mathbf{2 7}$ & 93
\end{tabular}

Given that $\mathrm{HCl}$ salt formation was not going to prove to be generally useful as a purification strategy, we turned our attention to forming the acetone hydrazones of the desired ACCs. This was done in a very straightforward way by treating an acetone solution of the crude reaction mixtures with $p-\mathrm{TsOH} \cdot \mathrm{H}_{2} \mathrm{O}$. In this way, the ACCs were converted to the corresponding hydrazones in high yield (Table 3). We also established that the crude amination reaction mixtures could be readily converted to the corresponding 3-pentanone-based ACC hydrazones 35-41. In all cases, the ACC hydrazones were 
obtained in high yield over the two step process, establishing that purification of the ACC prior to hydrazone formation is unnecessary.

We have previously demonstrateded ${ }^{7}$ that ACC 1 could be obtained from its acetone hydrazone (28) upon treatment with $\mathrm{HCl} \cdot \mathrm{H}_{2} \mathrm{NOH}$ in $\mathrm{THF}-\mathrm{H}_{2} \mathrm{O}(4: 1)$. Thus, using these conditions, but substituting EtOAc for THF - which gave a better result in the present case - each of the acetone-based hydrazones prepared according to Table 3 (28-34) was converted to its respective ACC (Table 4). In each case the desired product was obtained in excellent yield.

In conclusion, we have established that oxazolidiones are effectively $\mathrm{N}$-aminated to produce $\mathrm{N}$ amino cyclic carbamates (ACCs) using a combination of $t$ - $\mathrm{BuOK}$ and $\mathrm{NH}_{2} \mathrm{Cl}$. Not only is the monochloramine used in this procedure atom economical, but given that it is readily accessible from commercial bleach, it is also convenient and inexpensive. This mild and reliable procedure was applied to several oxazolidiones and in all cases the corresponding ACCs were obtained with excellent conversion. Conveniently, the crude reaction mixtures could be converted directly into hydrazones, for use in subsequent transformations.

\section{ACKNOWLEDGEMENTS}

We are grateful to the NSF (NSF 1300652), the Welch Foundation ((E-1806), and the University of Houston for financial support. S.E.W. thanks the NSF for a Graduate Fellowship.

\section{SUPPORTING INFORMATION}

Experimental procedures and analytical data for all new compounds. This material is available free of charge via the Internet at http://pubs.acs.org.

\section{REFERENCES}

1) Friestad, G. K.; Qin, J. J. Am. Chem. Soc. 2000, 122, 8329-8330.

2) (a) Qin, J.; Friestad, G. K. Tetrahedron 2003, 59, 6393-6402. (b) Friestad, G. K.; Marié, J.-C.; Deveau, A. M. Org. Lett. 2004, 6, 3249-3252. (c) Friestad, G. K.; Draghici, C.; Soukri, M.; Qin, J. J. Org. Chem. 2005, 70, 6330-6383. (d) Friestad, G. K. Eur. J. Org. Chem. 2005, 3157-3172. (e) Friestad, G. K.; Marié, J.-C.; Suh, Y.; Qin, J. J. Org. Chem. 2006, 71, 7016-7027. (f) Friestad, G. K.; Ji, A. Org. Lett. 2008, 10, 2311-2313. (g) Friestad, G. K.; Ji, A.; Baltrusaitis, J.; Korapala, C. 
S.; Qin, J. J. Org. Chem. 2012, 77, 3159-3180. (h) Slater, K. A.; Friestad, G. K. J. Org. Chem. 2015, 80, 6432-6440.

3) Friestad, G. K.; Qin, J. J. Am. Chem. Soc. 2001, 123, 9922-9923.

4) Friestad, G. K.; Ding, H. Angew. Chem. Int. Ed. 2001, 40, 4491-4493.

5) Cook, G. R.; Maity, B. C.; Kargbo, R. Org. Lett. 2004, 6, 1741-1743.

6) Jacobsen, M. F.; Ionita, L.; Skrydstrup, T. J. Org. Chem. 2004, 69, 4792-4796.

7) (a) Lim, D.; Coltart, D. M. Angew. Chem. Int. Ed. 2008, 47, 5207-5210. (b) Krenske, E. H.; Houk, K. N.; Lim, D.; Wengryniuk, S. E.; Coltart, D. M. J. Org. Chem. 2010, 75, 8578-8584. (c) Garnsey, M. R.; Lim, D.; Yost, J. M.; Coltart, D. M. Org. Lett. 2010, 12, 5234-5237. (d) Wengryniuk, S. E.; Lim, D.; Coltart, D. M. J. Am. Chem. Soc. 2011, 133, 8714-8720. (e) Garnsey, M. R.; Matous, J. A.; Kwiek, J. J.; Coltart, D. M. Bioorg. Med. Chem. Lett. 2011, 21, 2406-2409.

8) (a) Meyers, A. I.; Williams, D. R.; Druelinger, M. J. Am. Chem. Soc. 1976, 98, 3032-3033. (b) Hashimoto, S.; Koga, K. Tetrahedron Lett. 1978, 19, 573-576. (c) Meyers, A. I.; Williams, D. R. J. Org. Chem. 1978, 43, 3245-3247. (d) Hashimoto, S.; Koga, K. Chem. Pharm. Bull. 1979, 27, 2760-2766. (e) Meyers, A. I.; Williams, D. R.; Erickson, G. W.; White, S.; Druelinger, M. J. Am. Chem. Soc. 1981, 103, 3081-3087. (f) Enders, D.; Eichenauer, H.; Baus, U.; Schubert, H.; Kremer, K. A. M. Tetrahedron 1984, 40, 1345-1359. (g) Enders, D. Alkylation of chiral hydrazones. In Asymmetric Synthesis, 1st ed.; Morrison, J. D., Ed.; Academic Press: New York, 1984; Vol. 3, pp 275-339. (h) Job, A.; Janeck, C. F.; Bettray, W.; Peters, R.; Enders, D. Tetrahedron 2002, 58, 2253-2329.

9) (a) Shen, Y.; Friestad, G. K. J. Org. Chem. 2002, 67, 6236-6239. (b) Hynes, J.; Doubleday, W. W.; Dyckman, A. J.; Godfrey, J. D.; Grosso, J. A.; Kiau, S.; Leftheris, K. J. Org. Chem. 2004, 69, 1368-1371.

10) Thakkalapally, A.; Benin, V. Tetrahedron 2005, 61, 4939-4948.

11) Waddell, S. T.; Santorelli, G. M. Tetrahedron Lett. 1996, 37, 1971-1974.

12) Tuncbilek, M.; Schneller, S. W. Nucleosides Nucleotides \& Nucleic Acids 2003, 22, 1995-2001.

13) Kuang, R. Z.; Ganguly, A. K.; Chan, T. M.; Pramanik, B. N.; Blythin, D. J.; McPhail, A. T.; Saksena, A. K. Tetrahedron Lett. 2000, 41, 9575-9579.

14) Entwistle, I. D.; Wilby, A. H.; Johnstone, R. A. W. Tetrahedron, 1982, 38, 419-423.

15) Hynes, J.; Doubleday, W. W.; Dyckman, A. J.; Godfrey, J. D.; Grosso, J. A.; Kiau, S.; Leftheris, K. J. Org. Chem. 2004, 69, 1368-1371.

16) (a) Jaffari, G. A.; Nunn, A. J. J Chem. Soc. C 1971, 823-826. (b) Goehring, R. R. In Encyclopedia of Reagents for Organic Synthesis; Paquette, L. A., Ed; Wiley: New York, 1995; Vol. 2, pp 10521053. (c) See also: Theilacker, W.; Wegner, E. Angew. Chem. 1960, 72, 127-131.

17) The active reagent is assumed to be $\mathrm{NH}_{2} \mathrm{Cl}$ based on prior reports. See references 15 and 16. 


\section{T.O.C. Graphic}

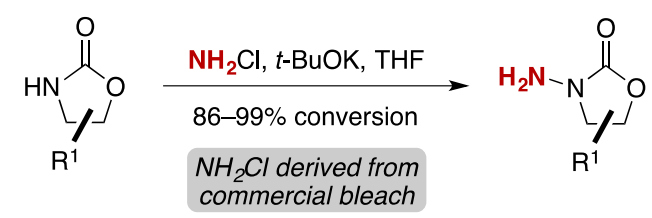

\section{Graphical Abstract}

